The three top injury-leading agricultural machines were Gyeong-ungi, tractor, and bush cutter.

Conclusion Agricultural machines were the main cause of occupational injuries for Korean farmers. Priority for prevention efforts should be given to more vulnerable populations (i. e., older males). For effective prevention, comprehensive strategies that incorporate engineering safety and improvement of agricultural working environment (e.g., farm road) as well as safety training and education are needed.

Funding Rural Development Administration, Republic of Korea (Project No. PJ 01001705).

\section{COMMUNITY-BASED FARM SAFETY INTERVENTION IN SOUTH KOREA}

K Kim*, D Choi, H Chae, H Kim, K Kim, K Lee. National Academy of Agricultural Science, Rural Development Administration, Jeonju, Republic of Korea

\subsection{6/oemed-2018-ICOHabstracts.56}

Introduction Intervention strategies to reduce agricultural injuries for self-employed farmers have been sought and evaluated in many prior studies. The aim of this study is to introduce the characteristics and effects of several types of farm safety interventions in South Korea.

Methods This study reviewed reports and documents of community-based farm safety interventions conducted by Korean central government through RDA (Rural Development Administration). The frameworks, main contents, effects, and implications of the intervention programs were described.

Results Since 2006, three main community-based farm safety intervention programs have been conducted by RDA, which were 'Farm Safety Model (2006-2015,133 farm villages)', 'Supporting Program of Farming Convenient Equipment (2008-2017, 1484 farm villages)', and 'Customised Farm safety Management Program (2015 current, 230 farmer’s cooperative units in 2015)'.

- 'Farm Safety Model' where professionals facilitated various interventions including farm safety education, an evaluation of risk factors on farm worksites, and health examination were apprised as effective in enhancing safety consciousness and safety management capacity of farmers.

- 'Supporting Program of Farming Convenient Equipment' was proved to reduce symptoms of musculoskeletal disorders among farmers participated.

- 'Customised Farm safety Management Program' that consisted of safety education, evaluation of risk factors on farm worksites, and customised supporting for occupational health and safety was evaluated as effective in enhancing the level of safety management on farming environment and hazards.

Conclusion Based on experiences from the existing intervention programs, the following are recommended for future strategies for agricultural health and safety: the main stream of community-based interventions is better to be farmers or farm leaders; intervention programs are recommended to contain both safety education/training and working environment interventions at least; national training programs and system for farm safety managers and farm leaders are needed.

Funding Rural Development Administration, Republic of Korea (Project No. PJ01250905).

\section{HYDROFLUORIC ACID: UPDATE ABOUT KNOWLEDGE ON EYE/SKIN AND RESPIRATORY EXPOSURE DAMAGES} AND DECONTAMINATION

${ }^{1}$ Laurence Mathieu*, ${ }^{1}$ François Burgher, ${ }^{2}$ Samuel Constant, ${ }^{2}$ Song Huang, ${ }^{3}$ Alan H Hall, ${ }^{1}$ Joël Blomet, ${ }^{4}$ Jean-Luc Fortin, ${ }^{5}$ NF Schrage. ${ }^{1}$ Prevor Laboratory Moulin de Verville 95760 Valmondois, France; '2Epithelix Sarl 14 Chemin des Aulx - CH-1228 Plan-les-Ouates, Geneva, Switzerland; ${ }^{3}$ Medical Toxicologist Toxicology Consulting and Medical Translating Services Springtown and Azle, Texas USA and Clinical Assistant Professor, Colorado School of Public Health, University of Colorado-Denver, Denver, Colorado, USA; ${ }^{4}$ Unité de médecine préventive -Ville de Saint-Etienne, 82 boulevard Bergson -42 000 Saint-Etienne; Centre des brûlés, Hôpital St-Luc-St-Joseph, 20 quai Cl. Bernard, 69365 Lyon Cedex 07; Service des Urgences, Hôpital d'Instruction des Armées de Desgenettes, 69000 Lyon; CAPTV, Hospices Civils de Lyon, 126 Boulevard Lacassagne, 69424 Lyon cedex 03; ${ }^{5}$ Augenklinik Köln Merheim; Acto Aachen, Germany

\subsection{6/oemed-2018-ICOHabstracts.57}

Introduction Hydrofluoric acid (HF) is very corrosive and toxic for humans by all routes of exposures.

Materials and methods Recent ex vivo studies have been conducted on eye, skin and respiratory track in order to determine the damages induced by HF. For respiratory effects, an experiment was designed to explore HF toxicological doses and effects on MucilAir ${ }^{\mathrm{m}}$, a unique 3D Human Airway Epithelia reconstructed in vitro. Review of current available literature on clinical data was also performed.

Results For inhalation exposure, up to $1.5 \mathrm{mM} \mathrm{HF}$, no toxic effect was detected. From $7.5 \mathrm{mM}$, damage to epithelia were observed but could be repaired 7 days after exposure. $75 \mathrm{mM}$ HF and above caused severe non reversible damage to epithelia. Ex Vivo Eye Irritation Test (EVEIT) combined with OCT allowed to characterise HF ocular burn with a complete diffusion into the cornea within $240 \mathrm{~s}$ for a $2.5 \%$ concentration. Ex Vivo study on human skin explants showed a diffusion in full skin within 5 min after a 70\% HF exposure. Decontamination on both eye/skin ex vivo models with water alone or with calcium gluconate limited the diffusion but did not prevent all damages, whereas decontamination with an hypertonic amphoteric exposure such Hexafluorine solution avoided the diffusion and damages. This result is in agreement with the analysis of the clinical results of the literature.

Conclusion Experimental models can help to understand chemical damages from HF exposures and design management based on new tools and devices in order to provide immediate and efficient decontamination to protect exposed workers.

\section{OBSTRUCTIVE SLEEP APNEA SYNDROME AND FITNESS TO DRIVE OF COMMERCIAL MOTOR VEHICLE DRIVERS - STATE-OF-THE-ART REVIEW}

WLC Van Hooste*. MD, Mediwet Occupational Health Services, External Service for Prevention and Protection at Work, Ghent, Belgium

\subsection{6/oemed-2018-ICOHabstracts.58}

Introduction Obstructive Sleep Apnea Syndrome (OSAS) is a very common disease with potentially severe health and social consequences. Untreated OSAS is associated with increased risk of motor vehicle accidents, caused by excessive daytime sleepiness (EDS). Sleepiness at the wheel is the cause of accident in 5 tot $7 \%$ of the cases. The overall risk of accidents for OSAS patients is elevated by a factor 2.4 to 3.7. OSAS is more common among commercial motor vehicle (CMV) drivers, due to obesitas for example. 